Journal for ImmunoTherapy of Cancer

\title{
Targeting disialoganglioside GD2 with chimeric antigen receptor-redirected $T$ cells in lung cancer
}

\author{
Loïc Reppel (D , , Ourania Tsahouridis, ${ }^{1}$ Jason Akulian, ${ }^{2}$ Ian J Davis, ${ }^{1,3}$ Hong Lee, ${ }^{1}$ \\ Giovanni Fucà (D) , Jared Weiss, ${ }^{1,4}$ Gianpietro Dotti, ${ }^{1,5}$ Chad V Pecot, ${ }^{1,4}$ \\ Barbara Savoldo ${ }^{1,3}$
}

To cite: Reppel L, Tsahouridis 0 , Akulian J, et al. Targeting disialoganglioside GD2 with chimeric antigen receptorredirected $\mathrm{T}$ cells in lung cancer. Journal for ImmunoTherapy of Cancer 2022;10:e003897. doi:10.1136/jitc-2021-003897

- Additional supplemental material is published online only. To view, please visit the journal online (http://dx.doi.org/10. 1136/jitc-2021-003897).

Accepted 14 November 2021

Check for updates

(C) Author(s) (or their employer(s)) 2022. Re-use permitted under CC BY-NC. No commercial re-use. See rights and permissions. Published by BMJ.

For numbered affiliations see end of article.

Correspondence to

Dr Barbara Savoldo;

bsavoldo@med.unc.edu

\section{ABSTRACT}

Background We explored whether the disialoganglioside GD2 (GD2) is expressed in small cell lung cancer (SCLC) and non-SCLC (NSCLC) and can be targeted by GD2specific chimeric antigen receptor (CAR) T cells. Methods GD2 expression was evaluated in tumor cell lines and tumor biopsies by flow cytometry and immunohistochemistry. We used a GD2.CAR that coexpress the IL-15 to promote T-cell proliferation and persistence, and the inducible caspase 9 gene safety switch to ablate GD2.CAR-T cells in case of unforeseen toxicity. The antitumor activity of GD2.CAR-T cells was evaluated using in vitro cocultures and in xenograft models of orthotopic and metastatic tumors. The modulation of the GD2 expression in tumor cell lines in response to an epigenetic drug was also evaluated.

Results GD2 was expressed on the cell surface of four of fifteen SCLC and NSCLC cell lines (26.7\%) tested by flow cytometry, and in $39 \%$ of SCLC, $72 \%$ of lung adenocarcinoma and $56 \%$ of squamous cell carcinoma analyzed by immunohistochemistry. GD2 expression by flow cytometry was also found on the cell surface of tumor cells freshly isolated from tumor biopsies. GD2. CAR-T cells exhibited antigen-dependent cytotoxicity in vitro and in vivo in xenograft models of GD2-expressing lung tumors. Finally, to explore the applicability of this approach to antigen low expressing tumors, we showed that pretreatment of GD2 ${ }^{\text {low/neg }}$ lung cancer cell lines with the Enhancer of zeste homolog 2 inhibitor tazemetostat upregulated GD2 expression at sufficient levels to trigger GD2.CAR-T cell cytotoxic activity.

Conclusions GD2 is a promising target for CAR-T cell therapy in lung cancer. Tazemetostat treatment could be used to upregulate GD2 expression in tumor cells, enhancing their susceptibility to CAR-T cell targeting.

\section{BACKGROUND}

Lung cancer is by far the leading cause of cancer death among both men and women worldwide, and the second most common cancer in terms of new cases. The American Cancer Society estimates 235,760 new cases and 131,880 deaths from lung cancer in the USA in 2021. ${ }^{1}$ Approximately $85 \%$ of lung cancer cases are non-small cell lung cancer (NSCLC), and the remaining $15 \%$ are small cell lung cancer (SCLC). In the USA, ethnic disparities exist with a 15\% higher lung cancer incidence in African Americans ${ }^{23}$

Although targeted therapies and checkpoint inhibitors have improved the outcome in lung cancer, the prognosis for most patients remains poor. The 5-year survival for localized NSCLC is $63 \%$, falling to $35 \%$ with regional spread, and to $7 \%$ with distant spread. ${ }^{4}$ The 5 -year survival for SCLC is even poorer: $27 \%$ for localized disease, $16 \%$ for regional disease and $3 \%$ for distant disease. ${ }^{4}$ The use of checkpoint inhibitors has improved outcomes, but recent data indicate that loss of HLA is a common mechanism of resistance to immune-based therapies. ${ }^{5}$ Newer, more effective treatments are thus needed.

Chimeric antigen receptor (CAR)-T cells have produced promising results in hematologic malignancies. ${ }^{6-8}$ However, the potential of CAR-T cells in solid tumors is limited by the paucity of targetable antigens unique to tumor cells and not shared with normal tissues, and by physical and immunosuppressive barriers. ${ }^{9} 10$ The disialoganglioside GD2, a non-protein target, is expressed on the cell surface of a wide spectrum of human cancers of neuroectodermal origin, such as neuroblastoma ${ }^{11}$ glioma ${ }^{12}$ and melanoma. ${ }^{13}$ Because of its restricted expression in normal tissues, GD2 represents an attractive target for cancer immunotherapy. ${ }^{14}{ }^{15}$ In particular GD2.CAR-T cells are actively being investigated in patients with neuroblastoma ${ }^{16-18}$ and melanoma. $^{19}$

GD2 has been reported to be expressed in SCLC $^{2021}$ and is associated with tumor cell proliferation and invasiveness. ${ }^{22}$ GD2 is also expressed in NSCLC, although more heterogeneously. ${ }^{23}$ Clinical studies of GD2 targeting agents in lung cancer have had mixed results. While the monoclonal antibody dinutuximab did not improve survival when combined 
with irinotecan, the bispecific T-cell engager AMG757 was associated with some objective responses. ${ }^{24} 25$ Thus, targeting GD2 may offer an effective therapeutic strategy for lung cancer. Here, we sought to explore the antitumor activity in vitro and in vivo of optimized GD2.CAR-T cells incorporating IL-15 to promote CAR-T cell expansion and persistence, and the inducible caspase 9 (iC9) safety switch gene to control unforeseen toxicities ${ }^{2627}$ in both SCLC and NSCLC using cell lines derived from both African American and Caucasian patients.

\section{METHODS \\ Cell lines}

SCLC and NSCLC cell lines were obtained from University of North Carolina (UNC) Tissue Culture Facility or purchased from American Type Culture Collection and UT Southwestern Medical Center. The Ewing's sarcoma cell line RD-ES was obtained from UNC Tissue Culture Facility. The neuroblastoma cell line CHLA255 was previously described. ${ }^{28}$ Cells were maintained in RPMI 1640 (Thermo Fisher Scientific) supplemented with 10\% fetal bovine serum (FBS) (Gemini Bio-Products), 1\% penicillin/streptomycin (Thermo Fisher Scientific), and 1\% GlutaMAX (Thermo Fisher Scientific) in a humidified $5 \% \mathrm{CO}_{2}$ atmosphere at $37^{\circ} \mathrm{C}$. RD-ES cells were cultured in medium supplemented with 15\% FBS. H446 and H2228 cells were transduced with a retroviral vector encoding the GFP-Firefly-Luciferase (GFP-FFluc) gene for tracking purposes. ${ }^{29}$ Cell lines were routinely tested to confirm the absence of mycoplasma and for the expression of the GD2 antigen by flow cytometry.

\section{Immunohistochemistry of human tissue microarrays}

Immunohistochemistry (IHC) was performed by the Pathology Service Core at UNC and carried out in the Bond fully automated slide staining system (Leica Microsystems). After pretreatment (epitope retrieval at pH 6.0 in Bond ER1 solution \#AR9961, 20 min), nonspecific binding in the tissue samples was blocked with 10 min incubation with Background Sniper (Biocare Medical, BS966M). Slides were then incubated for 1 hour with an anti-GD2 antibody (BD Pharmigen, cat\# 554272, Lot 9115547$)$ as primary antibody at 1:100 dilution. Detection was performed using Bond Intense R Detection kit (DS9263) supplemented with Novocastra Novolink Polymer Detection System (RE7200-K). Positive (staining of a neuroblastoma sample) and negative (staining without primary antibody) controls were included for each run. Stained slides were scanned at $20 \times$ magnification using the Aperio ScanScope-XT (Aperio Technologies, Vista, Californnia, USA) and images were uploaded to the Aperio eSlideManager database (Leica Biosystems Inc; eSlideManager V.12.4.3.5008) by the Translational Pathology Laboratory at UNC. Tissue microarray (TMA) slide images were digitally segmented into individual cores using Aperio TMA lab (Leica Biosystems). For whole tissue sections, tumor regions were manually annotated on images. All images were analyzed using the Aperio Cyto V.2 algorithm. The number and percentage of cells with light $(1+)$, medium $(2+)$ and strong (3+) nuclei and cytoplasmic staining were determined.

\section{Human lung tumor biopsies}

Deidentified lymph node or lung tumor fine-needle aspirates were obtained from patients with lung cancer after informed consent under an Institutional Review Board (IRB) approved protocol (UNC IRB 14-1755). Tumor tissues were classified as soft, medium or tough depending on their histological composition, weighed using a precision balance (Mettler Toledo, ML203E), filtered using 70 $\mu \mathrm{m}$ cell restrainers (Fisher) and enzymatically digested using specific human tumor dissociation kit following manufacturer's instruction (MACS Miltenyi Biotec; gentleMACS Octo Dissociator) into single-cell suspensions for subsequent flow cytometry analysis.

\section{Generation of CAR-T cells}

The cassette encoding the GD2-specific CAR, the IL-15 cytokine and the iC9 suicide gene (GD2.CAR) was previously described. ${ }^{26}$ As a control vector, the scFv14G2a of the GD2.CAR was swapped with the CD19-specific scFv ${ }^{27}$ to obtain the CD19-specific CAR encoding IL-15 and the iC9 suicide gene (CD19.CAR). Retroviral supernatants were prepared as previously reported.$^{29}$ Briefly, $293 \mathrm{~T}$ cells were transfected with the retroviral vector, the Peg-Pam-e plasmid encoding MoMLV gag-pol, and the RDF plasmid, encoding the RD114 envelope, using the GeneJuice transfection reagent (Merck Millipore), according to the manufacturer's instruction. Peripheral blood mononuclear cells isolated from healthy donors buffy coats (Gulf Coast Regional Blood Center, Houston, Texas, USA) by Lymphoprep density separation (Fresenius Kabi Norge) were activated with immobilized CD3 (Miltenyi Biotec) and CD28 (BD Biosciences) mAbs and transduced with retroviral supernatants as previously described. ${ }^{30}$ Cells were then expanded in complete medium (45\% Hyclone RPMI- $1640 \%$ and 45\% Click's medium,Irvine Scientific), 10\% FBS (Hyclone), $2 \mathrm{mM}$ GlutaMAX, 100 unit/mL of Penicillin and $100 \mathrm{mg} / \mathrm{mL}$ of streptomycin) with IL-7 (10 ng/mL; PeproTech) and IL-15 (5 ng/mL; PeproTech). ${ }^{30} 31$ On day $12-14$, cells were collected for in vitro and in vivo experiments.

\section{Coculture experiments}

Tumor cells were seeded in 24-well plates at a concentration of $0.25 \times 10^{6}$ cells/well. T cells were added to the culture at effector:target (E:T) ratios of $1: 2$ or $1: 5$ without the addition of exogenous cytokines. Cells were analyzed at day 5 to measure residual tumor cells and $\mathrm{T}$ cells by flow cytometry, using CD276 and CD3 antibodies, respectively. For each experiment, non-transduced T cells (NT) and CD19.CAR-T cells were used as negative controls. Supernatants were collected after 24 hours of coculture to measure the release of IFN $\gamma$ and IL-2, and, after 72 hours, of IL-15, using specific ELISA kits (R\&D system) 
following manufacturer's instructions. To assess proliferation, CAR-T cells were labeled with $1.5 \mathrm{mM}$ carboxyfluorescein diacetate succinimidyl ester (CFSE; Invitrogen) following the manufacturer's protocol and plated with tumor cells at an E:T ratio of 1:1. After 4 days, CFSE dilution was measured on gated $\mathrm{T}$ cells $\left(\mathrm{CD}^{+}\right.$cells $)$using flow cytometry.

\section{Immunophenotyping}

Monoclonal antibodies for CD276, CD3, CD19, CD45, CD45RA, CCR7, CD54 (ICAM1), CD71, CD326 (epithelial cell adhesion molecule, EpCAM), GD2 (Clone: 14.G2a) and PD-1 (BD Biosciences) were used. Expression of the CD19.CAR and GD2.CAR was detected using specific anti-idiotype scFv monoclonal antibodies ${ }^{2627}$ and APC-conjugated goat anti-mouse secondary mAbs (BD Biosciences). Cell number was quantified using CountBright Absolute Counting Beads (Thermo Fisher Scientific). Samples were acquired with BD FACSCanto II or BD FACSFortessa using the BD Diva software (BD Biosciences). For each sample a minimum of 10000 events were acquired. Data were analyzed using FlowJo V.10.

\section{Treatment of tumor cells with Enhancer of zeste homolog 2 inhibitor}

Tumor cell lines RD-ES, H748 and H1792 were seeded in 6 -well plates at $1 \times 10^{5}$ cells/well. Tumor cells were treated with the EZH2 (Enhancer of zeste homolog 2) inhibitor tazemetostat (EPZ-6438, KareBayBiochem, USA) dissolved in dimethyl sulfoxide (DMSO) or DMSO alone added at a concentration of 1 or $10 \mu \mathrm{M}$. RD-ES was used as a positive control. ${ }^{32}$ Cells were incubated at $37^{\circ} \mathrm{C}$ and $5 \% \mathrm{CO}_{2}$ for 21 days. When medium was changed or cells were split, the EZH2 inhibitor was replenished at the same concentrations. At days 7, 14 and 21, cells were harvested and analyzed for the GD2 expression by flow cytometry.

\section{Xenogeneic mouse models}

All mouse experiments were performed in accordance with UNC Animal Husbandry and Institutional Animal Care and Use Committee (IACUC) guidelines and were approved by UNC IACUC. For the lung cancer metastatic model, 8-10 weeks old mice (female and male) were injected intravenous with FFluc-H446 $\left(1 \times 10^{6}\right)$ tumor cells. Seven days after tumor cell inoculation, either CD19.CAR-T cells or GD2.CAR-T cells were injected intravenously ( 2 or $5 \times 10^{6}$ cells $/$ mouse). Fifty days after CAR-T cell treatment, mice received a second intravenous infusion of FFluc-H446 $\left(1 \times 10^{6}\right)$. For the lung cancer orthotopic model, 8-10 weeks old mice were orthotopically implanted in the lung with either FFlucH446 $\left(1 \times 10^{6}\right)$ or with FFluc-H2228 $\left(0.5 \times 10^{6}\right)$ tumor cells (1:1 mixture of Hank's Balanced Salt Solution and BD Matrigel (BD Biosciences). For the orthotopic injections, mice were anesthetized and placed in the right lateral recumbency. Following sterile skin preparation, an incision parallel to the rib cage between ribs 10 and 11 was made to visualize the lung through the intact thoracic pleura. Cell suspensions were injected directly into the lung parenchyma at the left lateral dorsal axillary line. After injection, the skin incision was closed using surgery clips, and the mice were turned on the left lateral recumbency and observed until fully recovered. On day 7 or 14 after tumor cell inoculation, CD19.CAR-T cells or GD2. CAR-T cells were injected intravenous ( 2 or $5 \times 10^{6}$ cells/ mouse). Mice were bled 21 days after T-cell infusion to evaluate T-cell persistence. Tumor growth was monitored by bioluminescence imaging (BLI) using the AMI system (Ami-HT model, Spectral Instruments Imaging). For all in vivo experiments CAR expression in the infused products ranged from 50\% to $75 \%$ and the T-cell dose was adjusted based on CAR expression. Mice were euthanized when tumor growth caused discomfort as per veterinarian's recommendation. At the time of euthanasia, blood, bone marrow and spleen were isolated and analyzed to detect and characterize $\mathrm{T}$ cells.

\section{Statistical analysis}

ANOVA (one way or two way) with Bonferroni correction and the unpaired and nonparametric Mann-Whitney test were used for comparison of three or more groups, or two groups, respectively. Measurements were summarized as mean $\pm \mathrm{SD}$ and experimental sample numbers (n) was indicated in the figure legends. Statistical significance was defined at $p<0.05$. Statistical analysis was performed with Prism V.9 (GraphPad Software).

\section{RESULTS \\ Expression of GD2 in human lung cancer cell lines, TMAs and primary lung cancer biopsies}

We analyzed eight SCLC and seven NSCLC established cell lines for GD2 expression by flow cytometry (online supplemental figure 1). Two SCLC cell lines (HCC2433 from an African American patient and $\mathrm{H} 446$ from a Caucasian patient) and two NSCLC cell lines (H727 from a Caucasian patient and H2228 from an individual of unspecified ethnicity) showed high GD2 expression for a total of $26.7 \%$ of the 15 cell lines analyzed (figure 1A). The H727 cell line showed the lowest GD2 Mean Fluorescence Intensity Ratio $(19.1 \pm 1.8)$ (figure 1B). The neuroblastoma cell line CHLA-255 and the H2122 lung cancer cell line were used as positive and negative controls for the GD2 expression, respectively. We developed an IHC protocol for GD2 detection and validated the staining using primary neuroblastoma samples (figure 1C). We applied this protocol to evaluate GD2 expression in SCLC $(\mathrm{n}=80)$ and NSCLC $(\mathrm{n}=253)$ TMAs. NSCLC included both lung adenocarcinoma (LUAD) $(\mathrm{n}=150)$ and lung squamous cell carcinoma (LUSC) $(\mathrm{n}=103)$. GD2 expression was found in $39 \%$ of SCLC, $72 \%$ of LUAD and $56 \%$ of LUSC (figure 1D). Similar to neuroblastoma, the majority of staining in lung cancer tumors was found within the cytoplasm, however some lung cancer tumors with weak cytoplasmic staining were found to have membranous staining. Of SCLC analyzed, 38\%, $1.3 \%$ and $0.04 \%$ of 
A
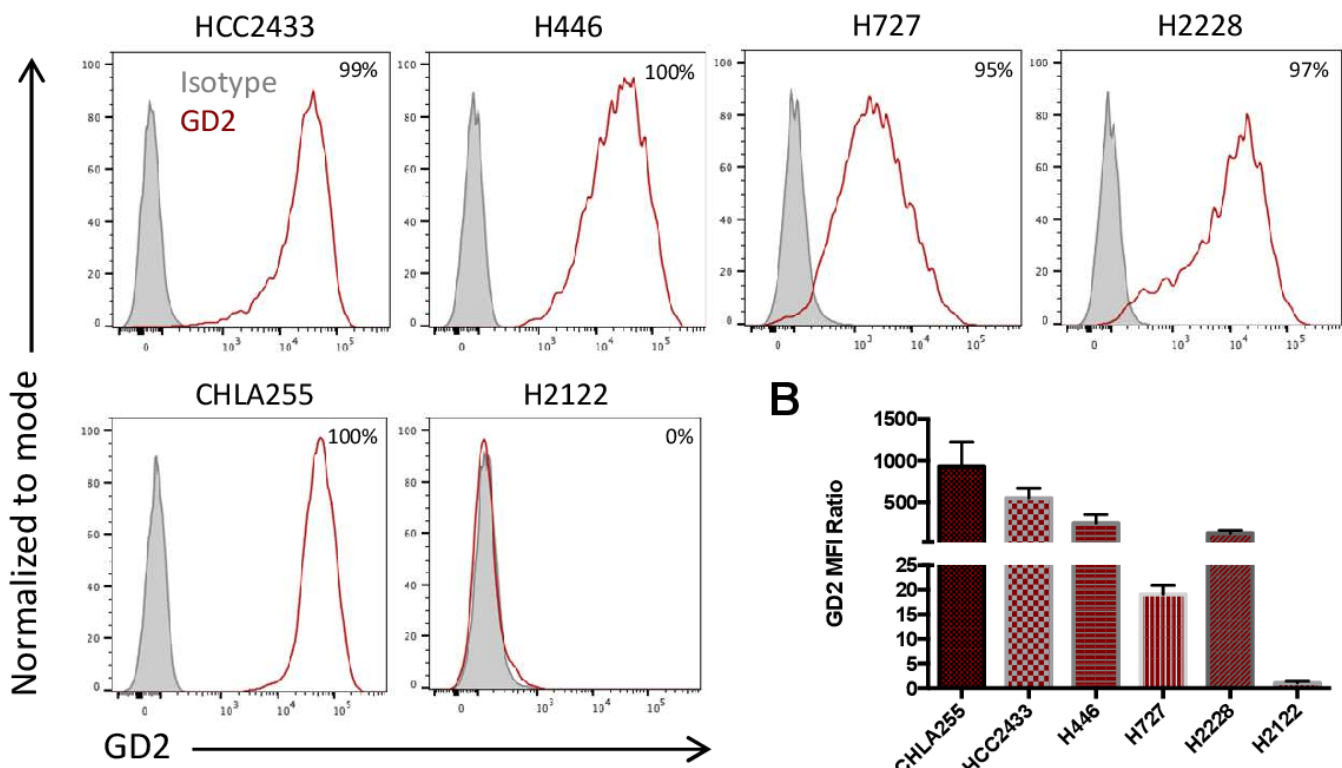

B

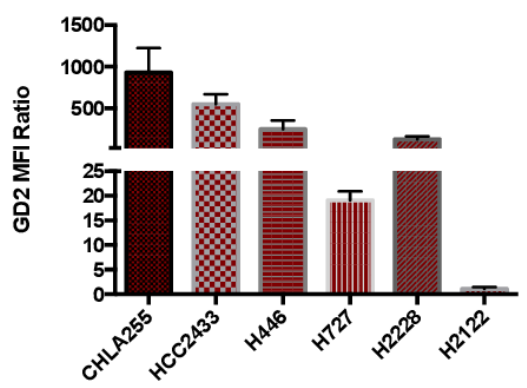

C

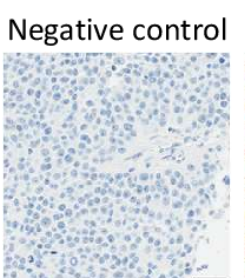

SCLC
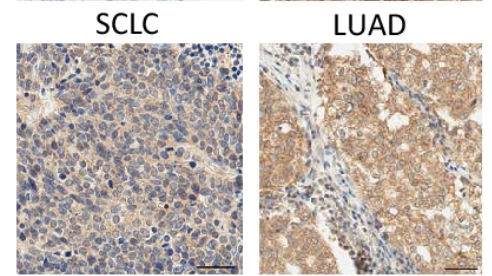

LUSC

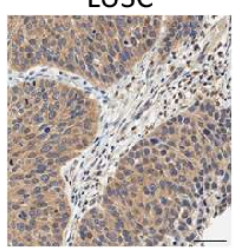

D

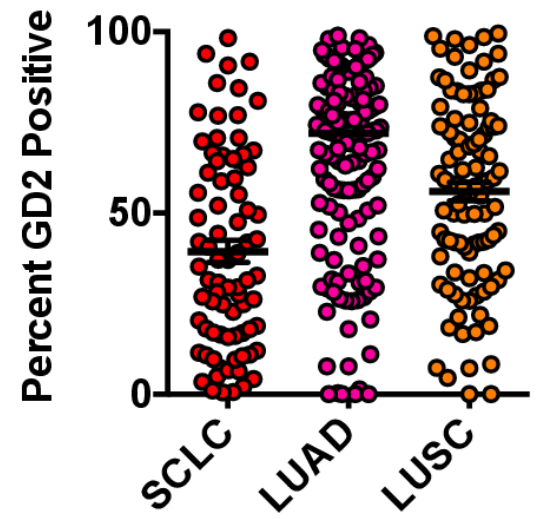

E

GD2 negative control

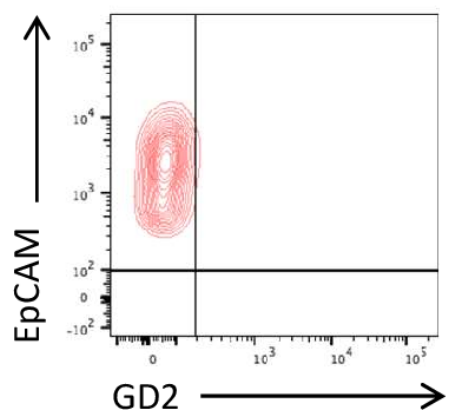

Lymph Node Biopsy

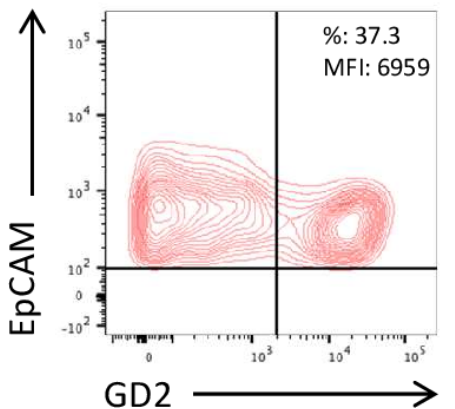

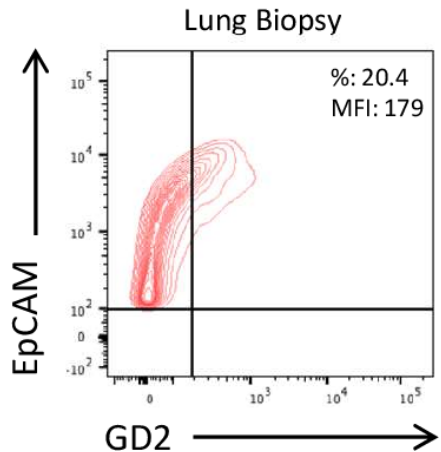

Figure 1 Expression of GD2 in human lung cancer cell lines, tissue microarray (TMA) and single cell suspensions obtained from lung cancer biopsies. (A, B) Expression of GD2 in SCLC (HCC2433 and H446) and NSCLC (H727 and H2228) cell lines as assessed by flow cytometry. The neuroblastoma cell line CHLA255 and the NSCL cell line H2122 were used as GD2-positive and GD2-negative control, respectively. The results are shown as percentages of positive cells (A) and GD2 mean fluorescent intensity (MFI) ratio (GD2 MFI/Isotype control MFI) (B). Data represent mean $\pm S D(n=3)$. (C) Representative IHC for GD2 expression in human TMA of SCLC and NSCLC including lung adenocarcinoma (LUAD) and lung squamous cell carcinoma (LUSC). Slides stained only with the secondary Ab were used as a negative control. Neuroblastoma was used as a positive control. Scale bars, $50 \mu \mathrm{m}$. (D) GD2 expression scores of the TMAs of SCLC ( $n=80)$, LUAD ( $n=150)$ and LUSC ( $n=103)$. (E) GD2 expression in cell suspensions obtained from lymph node or lung tumor fine-needle aspirates and assessed by flow cytometry. GD2 negative control is illustrated by the left panel. Tumor cells were identified by the expression of the epithelial cell marker EpCAM. EpCAM, epithelial cell adhesion molecule; NSCLC, non-small cell lung cancer; SCLC, small cell lung cancer. 
cells demonstrated light $(1+)$, medium $(2+)$ and strong (3+) GD2 cytoplasmic staining, respectively (figure 1D). For NSCLC, $56.6 \%, 6.1 \%$ and $0.2 \%$ of cells demonstrated light (1+), medium (2+) and strong (3+) GD2 cytoplasmic staining, respectively (figure 1D). We also analyzed GD2 expression by flow cytometry in cell suspensions obtained from fresh fine needle biopsies of lymph nodes or lung tumors of patients. In two samples in which epithelial cells were identifiable by the expression of EpCAM, 37.3\% and $20.4 \%$ of cells expressed GD2 (figure 1E). Overall, these data indicate that GD2 is expressed by both SCLC and NSCLC and that it can be detected on the cell surface by flow cytometry suggesting that tumor cells can be targeted by GD2.CAR-T cells.

\section{GD2.CAR-T cells target GD2 ${ }^{+}$human lung cancer cell lines in vitro}

The GD2-specific CAR used to target lung cancer encodes the CD28 endodomain, the IL-15 cytokine and the iC9 (GD2.CAR). The CD19-specific CAR encoding IL-15 and the iC9 (CD19.CAR) was used as a negative control (figure 2A). We generated GD2.CAR-T cells and control CD19.CAR-T cells from healthy donors, and both CARs were equally expressed $(70.3 \% \pm 4.4 \%$ and $61.6 \% \pm 10.2 \%$, respectively) (figure 2B,C). NT, CD19.CAR-T cells and GD2.CAR-T cells were tested for antitumor activity in coculture experiments against the GD2 ${ }^{+}$SCLC cell lines HCC2433 and H446, and the GD2 ${ }^{+}$NSCLC cell lines H727 and H2228. The GD2 ${ }^{-}$NSCLC cell line H2122 was used as a negative control, while the GD2 ${ }^{+}$neuroblastoma cell line CHLA-255 was used as a positive control. Only GD2.CAR-T cells completely eliminated GD2 ${ }^{+}$ target cells in coculture experiments, as indicated by tumor cells remaining in the culture by flow cytometry at day 5 of culture (figure 2D,E). The cytolytic activity of GD2.CAR-T cells was corroborated by cytokines release (IFN $\gamma$, IL-2 and IL-15) detected in the culture supernatant by ELISA (figure $2 \mathrm{~F}-\mathrm{H}$ ) and by T-cell proliferation in response to GD2 ${ }^{+}$target cells, as assessed by CFSE dilution (figure 2I,J). No significant tumor elimination, cytokine release and T-cell proliferation were observed for control $\mathrm{T}$ cells or CD19.CAR-T cells. Overall these data indicate that GD2.CAR-T cells can proliferate, release proinflammatory cytokines and eliminate human lung cancer cell lines expressing GD2.

\section{GD2.CAR-T cells target GD2 ${ }^{+}$lung cancer in orthotopic and metastatic xenograft models}

To assess the antitumor activity of GD2.CAR-T cells in vivo we established SCLC and NSCLC orthotopic and metastatic models. For the orthotopic models, NOD (nonobese diabetic) scid gamma (NSG) mice were engrafted with the SCLC cell line FFluc-H446 (figure 3A). Tumor BLI showed tumor engraftment at day 7 , at which time mice were treated with CAR-T cells administered via tail vein injection (figure 3B). Sequential measurements of tumor BLI showed that GD2.CAR-T cells controlled tumor growth significantly better than CD19.CAR-T cells up to day 98 when the experiment was terminated (figure 3B,C). No significant dose effect of GD2.CAR-T cells was observed, as tumor control occurred equally in mice infused with $2 \times 10^{6}$ or $5 \times 10^{6}$ CAR-T cells. However, the dose of GD2.CAR-T cell affected the amount of circulating CAR-T cells measured at day 21 after CAR-T cell infusion, with circulating $\mathrm{T}$ cells being detected at higher frequency in mice treated with GD2.CAR-T cells at the $5 \times 10^{6}$ dose compared with the $2 \times 10^{6}$ dose. By phenotypic characterization, the majority of the circulating $\mathrm{T}$ cells were terminally differentiated effectors (TEMRA, CCR7 CD45RA ${ }^{+}$) with a third expressing PD-1. However, a subset of $\mathrm{T}$ cells remained CCR $7^{+} \mathrm{CD} 45 \mathrm{RA}{ }^{+}(7 \% \pm 4 \%)$ resembling stem cell memory $\mathrm{T}$ cells ${ }^{31}$ (figure 3D,E). At the time of euthanasia, at day 100 post-treatment, $\mathrm{T}$ cells were still detectable in the blood, bone marrow and spleen and were more prominent in mice treated with the dose of $5 \times 10^{6}$ of GD2.CAR-T cells (figure 3F). In a second orthotopic tumor model, mice were engrafted in the lung with the FFluc-H2228 NSCLC cell line (figure 3G). Tumor BLI showed engraftment 14 days after inoculation, at which time mice were treated with CAR-T cells administered via tail vein injection (figure $3 \mathrm{H}$ ). Also in this tumor model, GD2.CAR-T cells controlled tumor growth significantly better than control CD19.CAR-T cells, regardless of the GD2.CAR-T cell dose used (figure 3H,I). Also in this model, the phenotypic characterization of circulating $\mathrm{T}$ cells confirmed the presence of $\mathrm{CCR} 7^{+} \mathrm{CD} 45 \mathrm{RA} \mathrm{A}^{+}$ in the peripheral blood at day 21 after CAR-T cell infusion (figure 3K). At the time of euthanasia, at day 65 post-treatment, T cells were still detectable in the blood, bone marrow and spleen (figure 3L). When analyzed by flow cytometry, all tumors isolated from mice treated with CD19.CAR-T cells retained GD2 expression (online supplemental figure 2A). In contrast, when we analyzed a tumor from a mouse implanted orthotopically with FFlucH446 tumor cells that relapsed after treatment with GD2. CAR-T cells at $2 \times 10^{6}$ (figure 3B) we observed GD2 loss (online supplemental figure 2B).

We next evaluated the in vivo antitumor activity of GD2. CAR-T cells in a metastatic model of SCLC in which NSG mice were inoculated intravenously with the SCLC cell line FFluc-H446 (figure 4A). By day 28-35, mice treated with control CD19.CAR-T cells, showed high tumor BLI signals in the lower abdomen and liver, whereas 9 of the 10 mice treated with GD2.CAR-T cells remained tumor free up to day 49, regardless of the CAR-T cell dose used $\left(2 \times 10^{6}\right.$ or $5 \times 10^{6}$ cells) (figure $\left.4 \mathrm{~B}, \mathrm{C}\right)$. Three weeks after CAR-T cell infusion only GD2.CAR-T cells were detected in the peripheral blood, and more than $65 \%$ of $\mathrm{T}$ cells expressed the GD2.CAR (online supplemental figure 3). The phenotypic characterization of circulating $\mathrm{T}$ cells showed that the majority were CCR7 CD $45 \mathrm{RA}^{+}$and half of them expressed PD-1, but a subset of cells remained CCR $7{ }^{+} \mathrm{CD} 45 \mathrm{RA}^{+}(20.1 \% \pm 19.8 \%)$ (online supplemental figure 3 ). On day 50 after CAR-T cell infusion, no circulating $\mathrm{T}$ cells were found in mice treated with CD19. CAR-T cells, while T cells were detectable in mice treated 
A

\begin{tabular}{|c|c|c|c|c|c|c|c|c|c|c|}
\hline LTR & iCaspase-9 & $2 \mathrm{~A}$ & scFv.14g2a & hTM-CD8 $\alpha$ & CD28 & СDЗ५ & $2 \mathrm{~A}$ & |L-15 & $3^{\prime}$ LTR & $\begin{array}{l}\text { iC9.GD2.CAR.IL15 } \\
9683 \text { bp }\end{array}$ \\
\hline 5' LTR & Caspase-9 & $2 \mathrm{~A}$ & scFv.CD19 & hTM-CD8 $\alpha$ & CD28 & $\mathrm{CD} 3 \zeta$ & $2 \mathrm{~A}$ & IL-15 & ,' LTR & $\begin{array}{l}\text { iCg.CD19.CAR.IL15 } \\
10260 \text { bp }\end{array}$ \\
\hline
\end{tabular}
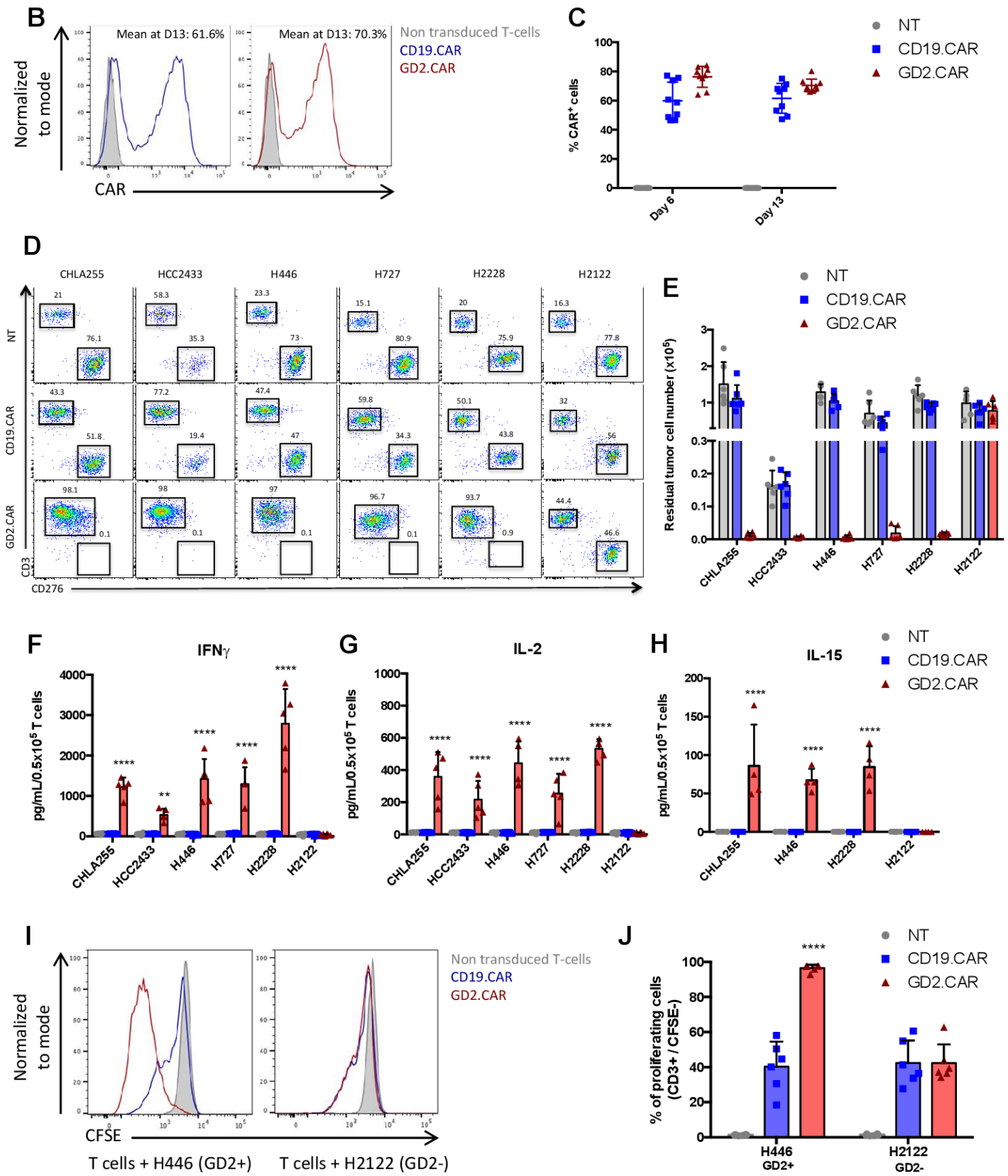

Figure 2 GD2.CAR-T cells target GD2 ${ }^{+}$human lung cancer cell lines in vitro. (A) Schematic representation of retroviral vectors encoding the GD2-specific CAR with the CD28 endodomain, IL-15 cytokine and iCaspase-9 (GD2.CAR) and the CD19-specific CAR with IL-15 cytokine and iCaspase-9 (CD19.CAR) which was used as a control. (B) Flow cytometry histograms showing CAR expression for one representative experiment. Expression is represented relative to non transduced control T cells (NT). (C) Summary of the CAR expression at day 6 and day 13 after T-cell activation. Data represent mean $\pm S D(n=9)$. (D, E) Lung cancer cell lines were cocultured with NT, CD19.CAR-T cells or GD2.CAR-T cells at the T-cell to tumor cell ratio of 1 to 5 . On day 5, tumor cells $\left(\mathrm{CD} 276^{+}\right)$and T cells $\left(\mathrm{CD}^{+}\right)$were enumerated by flow cytometry. The neuroblastoma cell line CHLA255 was used as $\mathrm{GD}^{+}$control. Representative flow-cytometry plots (D) and quantification of residual tumor cells $(\mathrm{E})$ are illustrated. Data represent mean $\pm S D(n=6)$. $(F-H)$. Summary of IFN $\gamma(F)$ and IL-2 $(G)$ released by NT, CD19.CAR-T cells or GD2.CAR-T cells in supernatants after 24 hours, and of IL-15 after 72 hours $(\mathrm{H})$, of coculture with the indicated tumor cell lines as measured by specific ELISAs. Data represent mean $\pm S D\left(n=4-6,{ }^{* \star} \mathrm{p}<0.01 ;{ }^{* * *} \mathrm{p}<0.0001, \mathrm{GD} 2\right.$.CAR vs CD19.CAR). (I, J). Representative CFSE dilution of CFSE-labeled NT, CD19.CAR-T cells or GD2.CAR-T cells cocultured with the GD2 ${ }^{+}$tumor cell line $\mathrm{H} 446$ or the GD2 tumor cell line $\mathrm{H} 2122$ for 4 days at 1 to 1 ratio and analyzed by flow cytometry (I). CFSE dilution was measured relative to CFSE-labeled NT. Summary of the CFSE dilution assays (J). Data represent mean $\pm S D\left(n=6,{ }^{* \star * \star} p<0.0001\right.$, GD2.CAR vs CD19. CAR). CAR, chimeric antigen receptor; CFSE, carboxyfluorescein diacetate succinimidyl ester. 

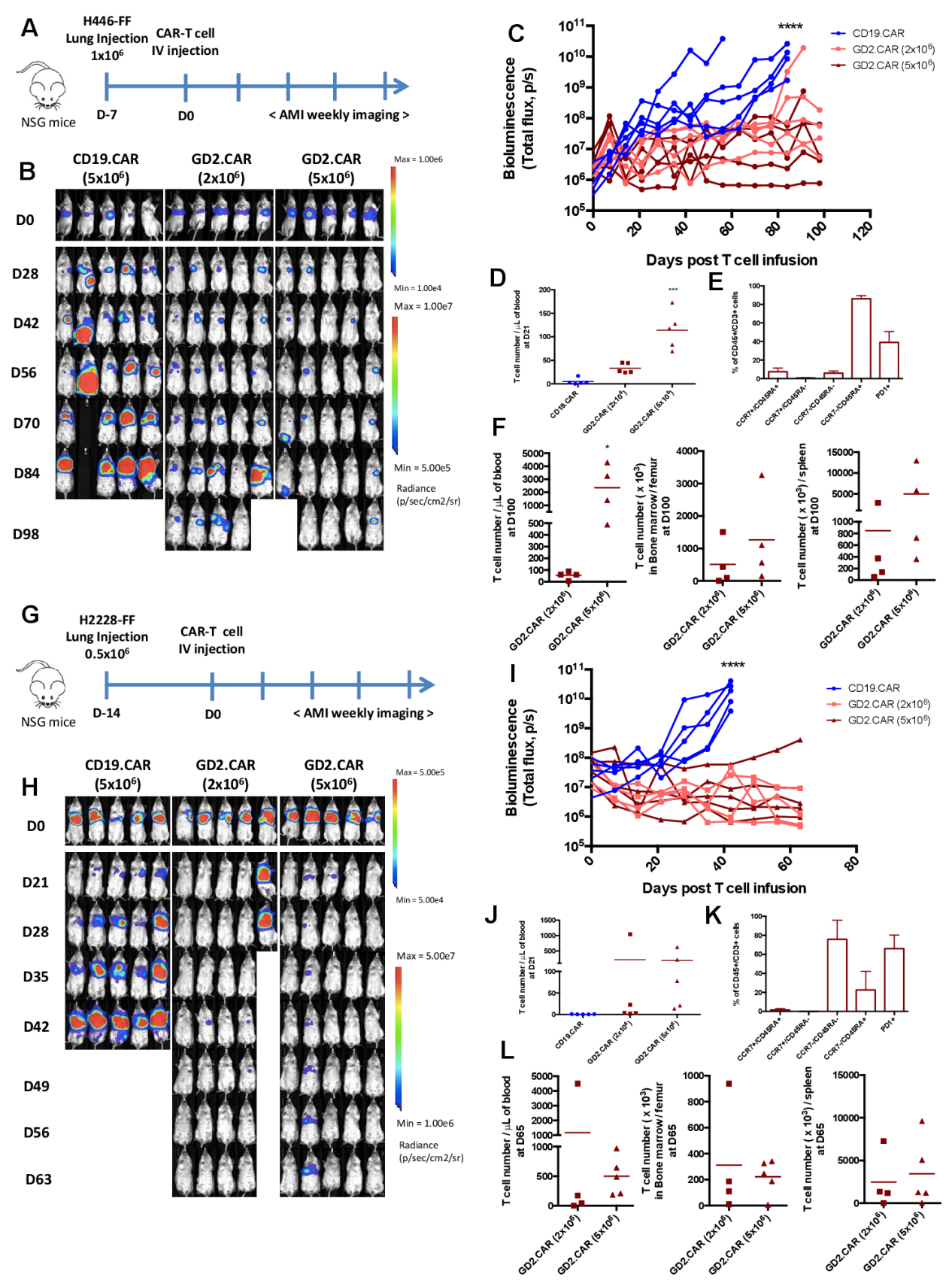

Figure 3 GD2.CAR-T cells target GD2 ${ }^{+}$SCLC and NSCLC in orthotopic xenograft models. (A) Schematic representation of the SCLC orthotopic xenograft model. Mice were injected into the lung with FFluc-H446 $\left(1 \times 10^{6}\right)$ tumor cells. Seven days after tumor cell inoculation, either CD19.CAR-T cells or GD2.CAR-T cells were injected intravenously ( 2 or $5 \times 10^{6}$ cells/mouse). $(B, C)$ Representative bioluminescence images (BLI) $(B)$ and BLI kinetics $(C)$ of the FFluc-H446 tumor growth in the SCLC orthotopic model described in (A); $(n=5),{ }^{* * * *} \mathrm{p}<0.0001$, GD2.CAR $\left(2 \times 10^{6}\right.$ cells) vs CD19.CAR and GD2.CAR $\left(5 \times 10^{6}\right.$ cells) vs CD19.CAR). (D, E) Quantification ( $\left.C D 45^{+} \mathrm{CD}^{+}\right)(\mathrm{D})$ and phenotype $(\mathrm{E})$ of T cells in peripheral blood samples collected 21 days after infusion in the SCLC orthotopic model described in $(A) ;(n=5)$, ${ }^{* * *} \mathrm{p}<0.001$, GD2.CAR $\left(5 \times 10^{6}\right.$ cells) vs CD19.CAR and GD2. CAR $\left(5 \times 10^{6}\right.$ cells) vs GD2.CAR $\left(2 \times 10^{6}\right.$ cells). (F) Quantification of T cells $\left(C D 45^{+} \mathrm{CD}^{+}\right)$in blood, bone marrow and spleen at the time of euthanasia ( 100 days after CAR-T cell infusion); $(n=4)$, ${ }^{*} p<0.05$, GD2.CAR $\left(5 \times 10^{6}\right.$ cells) vs GD2.CAR $\left(2 \times 10^{6}\right.$ cells). (G) Schematic representation of the NSCLC orthotopic xenograft model. Mice were injected into the lung with FFluc-H2228 $\left(0.5 \times 10^{6}\right)$ tumor cells. Fourteen days after tumor cell inoculation, either CD19.CAR-T cells or GD2.CAR-CAR-T cells were injected intravenous ( 2 or $5 \times 10^{6}$ cells/mouse). ( $\left.\mathrm{H}, \mathrm{l}\right)$ Representative $\mathrm{BLI}(\mathrm{H})$ and BLI kinetics (I) of the FFluc-H2228 tumor growth in the NSCLC orthotopic model described in $(G) ;(n=4-5)$, ${ }^{* \star *} p<0.0001$, GD2.CAR $\left(2 \times 10^{6}\right.$ cells) vs CD19.CAR and GD2.CAR $\left(5 \times 10^{6}\right.$ cells) vs CD19.CAR). (J, K) Quantification of the T cells $\left(C D 45^{+} \mathrm{CD}^{+}\right)(\mathrm{J})$ and their phenotype $(\mathrm{K})$ in peripheral blood samples collected 21 days after CAR-T cells in the NSCLC orthotopic model described in (G). (L) Quantification of T cells $\left(\mathrm{CD} 45^{+} \mathrm{CD}^{+}\right)$in blood, bone marrow and spleen at the time of euthanasia (65 days after CAR-T cell infusion). Data illustrated are representative of two independent experiments for each model. CAR, chimeric antigen receptor; NSCLC, non-small cell lung cancer; NSG, NOD (non-obese diabetic) scid gamma; SCLC, small cell lung cancer. 
A

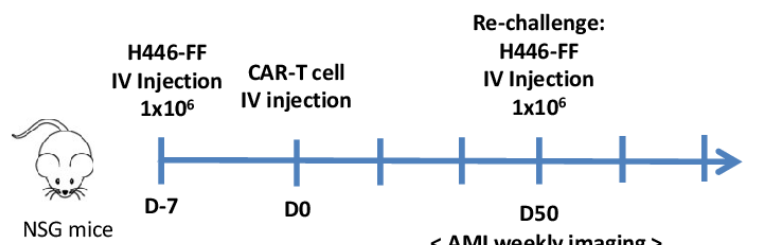

B

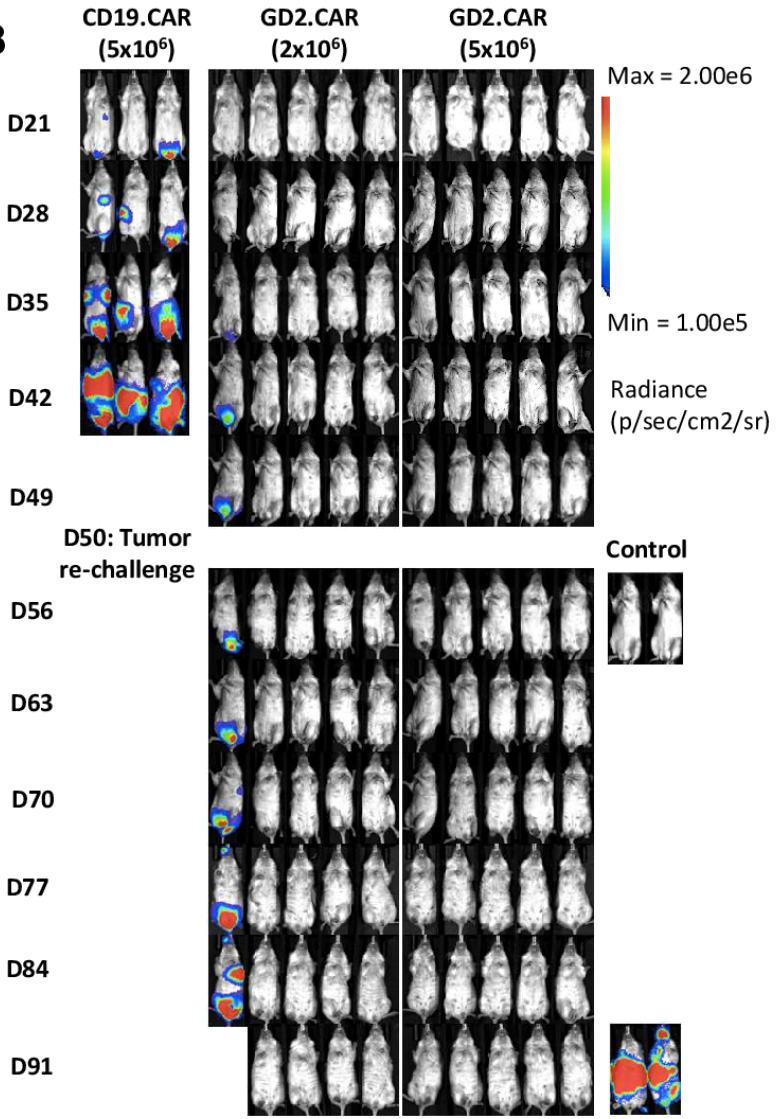

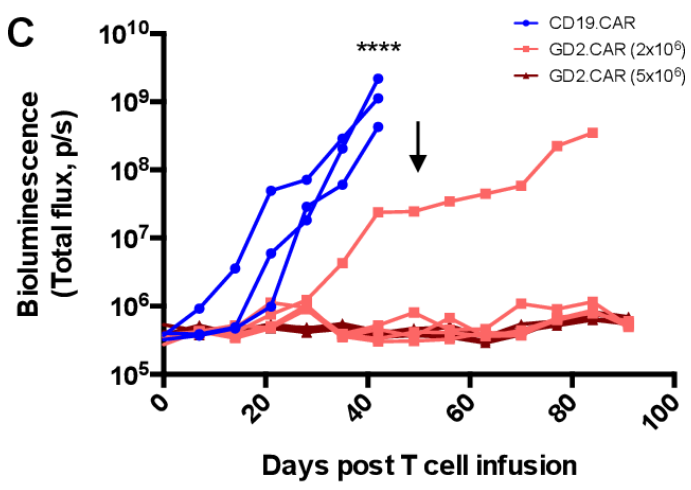

D

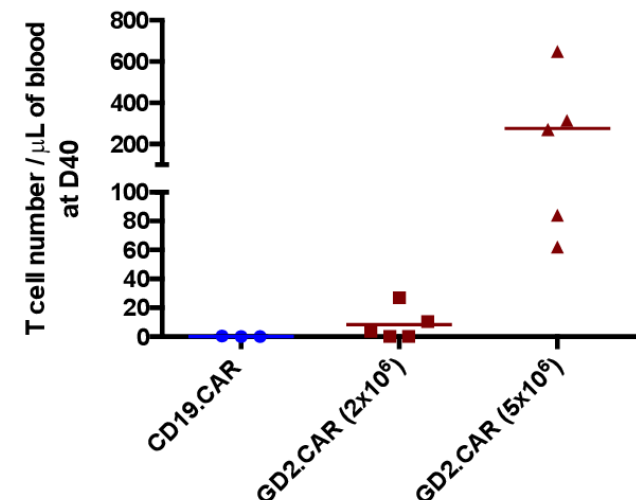

$\mathbf{F}$

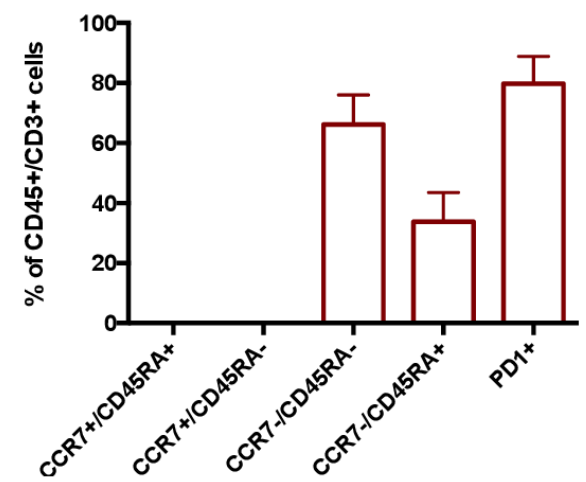

E

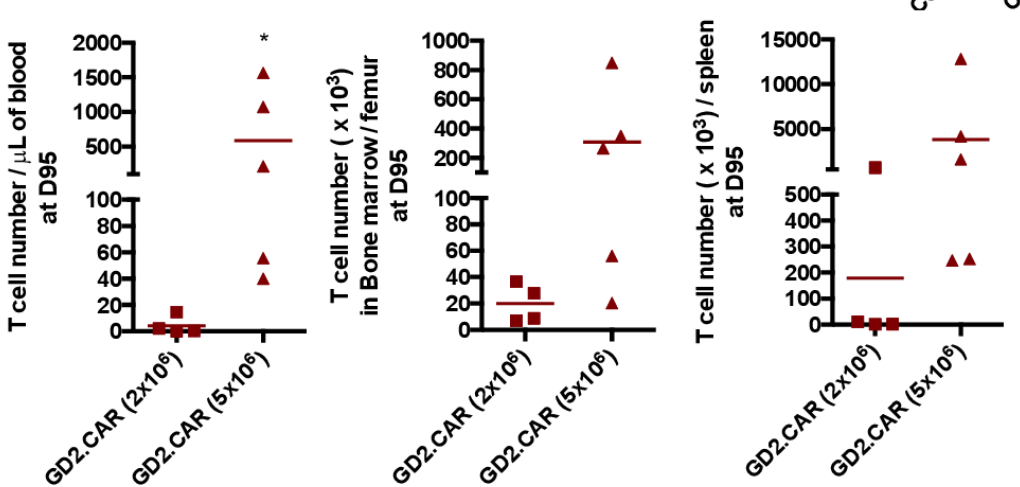

Figure 4 GD2.CAR-T cells target GD2 ${ }^{+}$SCLC in metastatic xenograft model. (A) Schematic representation of the SCLC metastatic xenograft model. Mice were injected intravenous with FFluc-H446 $\left(1 \times 10^{6}\right)$ tumor cells. Seven days after tumor cell inoculation, either CD19.CAR-T cells or GD2.CAR-T cells were injected intravenously ( 2 or $\left.5 \times 10^{6} \mathrm{cells} / \mathrm{mouse}\right)$. Tumor free mice at day 50 received tumor rechallenge by inoculating FFluc-H446 $\left(1 \times 10^{6}\right)$ tumor cells. At the time of the tumor re-challenge two mice were used as control to show engraftment of the tumor cells used for the rechallenge. (B, C) Representative $B L I$ images (B) and BLI kinetics (C) of the FFluc-H446 tumor growth; $(n=3-5)^{* * * *} p<0.0001$, GD2.CAR $\left(2 \times 10^{6}\right.$ cells) vs CD19.CAR and GD2.CAR $\left(5 \times 10^{6}\right.$ cells) vs CD19.CAR. Arrow indicates the time in which tumor rechallenge was performed. (D) Quantification of circulating T cells $\left(\mathrm{CD} 45^{+} \mathrm{CD}^{+}\right)$at day 40 after CAR-T cell infusion. Quantification (CD45 $\left.{ }^{+} \mathrm{CD}^{+}\right)(\mathrm{E})$ and phenotypic characterization ( $\mathrm{F}$ ) of T cells in blood, bone marrow and spleen at the time of euthanasia at day 95 after CAR-T cell treatment; $(n=4-5),{ }^{*} p<0.05$, GD2.CAR $\left(5 \times 10^{6}\right.$ cells $)$ vs GD2.CAR $\left(2 \times 10^{6}\right.$ cells). BLI, bioluminescence imaging; CAR, chimeric antigen receptor; NSG, NOD (non-obese diabetic) scid gamma; SCLC, small cell lung cancer. 
with GD2.CAR-T at the dose of $5 \times 10^{6}$ cells (figure 4D). Mice showing tumor control, were re-challenged with FFluc-H446 cells on day 50. GD2.CAR-T cells continued to control tumor growth, since mice remained tumor free up to 90 days after treatment. At the time of euthanasia, at day 95 post-treatment, $\mathrm{T}$ cells were still detectable in the blood, bone marrow and spleen and more prominent in mice treated with GD2.CAR-T at the dose of $5 \times 10^{6}$ and having received the tumor re-challenge (figure $4 \mathrm{E}$ ). The phenotypic characterization of circulating $\mathrm{T}$ cells of this group showed that the cells exhibited effector-memory markers and $79.8 \% \pm 9.1 \%$ expressed PD-1 (figure $4 \mathrm{~F}$ ). We attempted to establish a metastatic model using the NSCLC H2228 tumor cell line, but most of the mice experienced cardiac arrest immediately after the intravenous inoculation of the tumor cells likely due to the large size of these cells. Overall, these data indicate that GD2. CAR-T cells can control tumor growth of lung cancer in both orthotopic and metastatic models and that these cells are protective against tumor rechallenge.

\section{Inhibition of EZH2 in GD2 ${ }^{\text {low/neg }}$ lung cancer cell lines increases GD2 expression}

Due to the heterogeneous expression of GD2 in lung cancer, we sought to determine the effect of the EZH2 inhibitor tazemetostat on lung cancer since it upregulates GD2 expression in Ewing sarcoma cell lines. ${ }^{32}$ We cultured the GD2 ${ }^{\text {low/neg }}$ SCLC cell line H748 and the NSCLC cell line H1792 with tazemetostat at 1 or $10 \mu \mathrm{M}$, respectively, or equivalent volumes of control DMSO (figure 5A). The Ewing sarcoma cell line RD-ES was used as a positive control. Both H748 and H1792 cell lines showed increased GD2 expression after 21 days of exposure to tazemetostat (from $8 \%$ to $70 \%$ and from $6 \%$ to $34 \%$, respectively) (figure 5A). Lung cancer cell lines pretreated with tazemetostat or DMSO for 21 days were then cocultured with either CD19.CAR-T cells or GD2.CAR-T cells at the T-cell to tumor cell ratio of 1 to 2. Lung cancer cell lines pretreated with tazemetostat became sensitive to GD2.CAR-T cell cytotoxicity in coculture experiments, as shown by the reduction of tumor cells remaining at day 5 of coculture by flow cytometry (figure 5B). Cytolytic activity of GD2.CAR-T cells was corroborated by cytokine release (IFN $\gamma$ and IL-2) in the culture supernatant (figure 5C,D) and by T-cell proliferation (figure $5 \mathrm{E}, \mathrm{F}$ ), as assessed by CFSE dilution assay. Overall these data indicate that tazemetostat can promote GD2 upregulation in lung cancer cells and enhance their susceptibility to the cytotoxic effects of CAR-T cells.

\section{DISCUSSION}

Due to its restricted expression in normal tissues, GD2 offers an attractive target for cancer immunotherapy using CAR engineered immune cells in neuroblastoma $\left(\right.$ NCT00085930, NCT03721068) ${ }^{1733}$ and melanoma (NCT02107963). ${ }^{19}$ Here, we report that GD2.CAR-T cells promote antitumor activity in vitro and in vivo in both SCLC and NSCLC models.

Adoptive antitumor immunotherapy using T cells seeks to provide long-term tumor control. Sustainable antitumor activity of infused $\mathrm{T}$ cells is directly correlated with their proliferation and persistence in vivo, which depend on the differentiation and exhaustion profile of T cells. ${ }^{34}$ Incorporation of the IL-15 cytokine within the CAR construct produces an enrichment of cells with "memory" and 'stem-cell' like phenotypes, and provides enhanced antigen-independent expansion and persistence in tumor sites and improved antitumor activity. ${ }^{26} 35$

The disialoganglioside GD2, a non-protein target, is expressed on the cell surface of a wide spectrum of human cancers. ${ }^{14}$ GD2 has been previously described as expressed in a majority of human SCLC tumors. ${ }^{20}{ }^{21}$ However, limited information are available on the expression of GD2 by NSCLC tumors. Our IHC analysis of human NSCLC TMAs is the first to demonstrate that both LUAD and LUSC express the GD2 antigen. We screened SCLC and NSCLC cell lines derived from Caucasian and African American individuals and verified the expression of GD2. We then showed that both SCLC and NSCLC cell lines can be targeted in vitro and in vivo by GD2.CAR-T cells. In orthotopic lung cancer models of both SCLC and NSCLC, GD2.CAR-T cells, delivered intravenously, effectively exhibited antitumor activity. Similar effective antitumor activity was observed in a disseminated tumor model. Because our construct contains a gene encoding for IL-15, the persistence of CAR-T cells in vivo was sustained, and promoted antitumor activity in tumor rechallenge experiments, as previously observed with another tumor type. ${ }^{26}$

When targeting a single antigen, tumor antigen heterogeneity is a potential resistance mechanism as low or negative subsets of tumor cells are expected to escape CAR-T cell targeting. Assessment of GD2 expression in biopsies from patient-derived lung cancer samples identified some degree of heterogeneity. Furthermore, we recently reported in a model of neuroblastoma that tumor escape can occur when tumor cells express low levels of GD2. ${ }^{36}$ Recent efforts have been directed into exploring pharmaceutical strategies to increase antigen expression. ${ }^{37}$ For example, in neuroblastoma GD2, although uniformly expressed, can be further upregulated in vitro in the presence of the HDAC inhibitor vorinostat. ${ }^{38}$ Using an alternative epigenetic modulator, Kailayangiri $e t a \vec{l}^{2}$ showed that GD2-low/negative Ewing sarcoma cells increased their GD2 surface expression to levels susceptible for effective antigen-specific activation of GD2.CAR-T cells. For the first time, we here show that in GD2 ${ }^{\text {low } / \text { neg }}$ SCLC and NSCLC cell lines, GD2 can be upregulated after exposure to the EZH2 inhibitor tazemetostat in vitro, making these lung tumor cells sensitive to GD2.CAR-T cells. However, tumor cells required long-term treatment with tazemetostat to modulate GD2 expression, limiting our capacity to test the combination of tazemetostat and CAR-T cells in vivo. Nevertheless, the proposed therapeutic strategy should be feasible in patients since epigenetic regulators are clinically available. The combination of GD2. 
A

RD-ES

$\mathrm{H} 748$

$\mathrm{H} 1792$

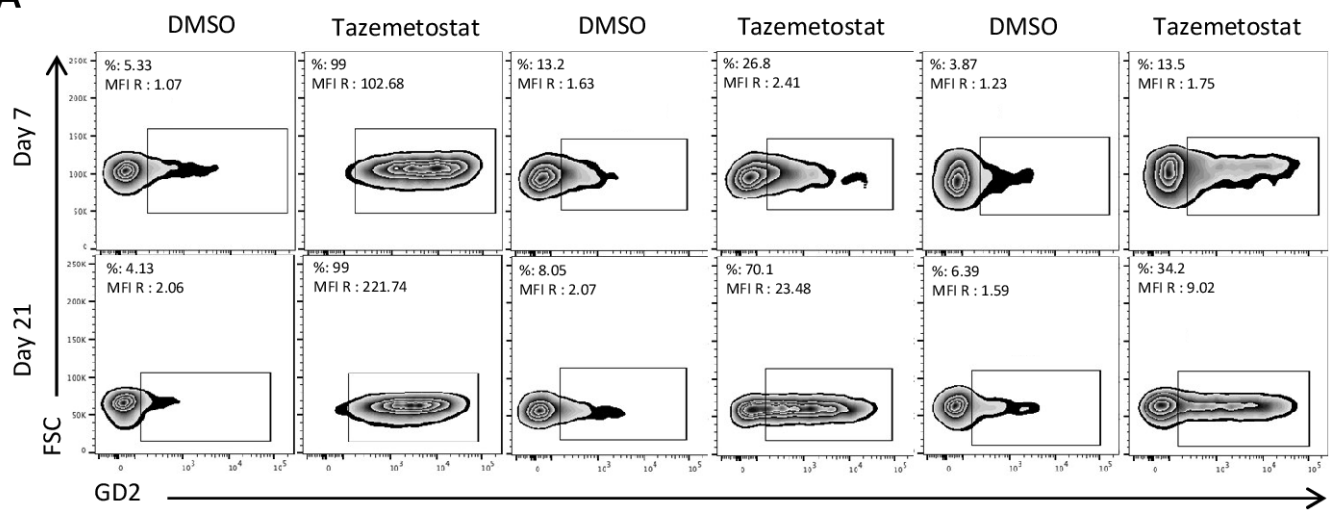

B

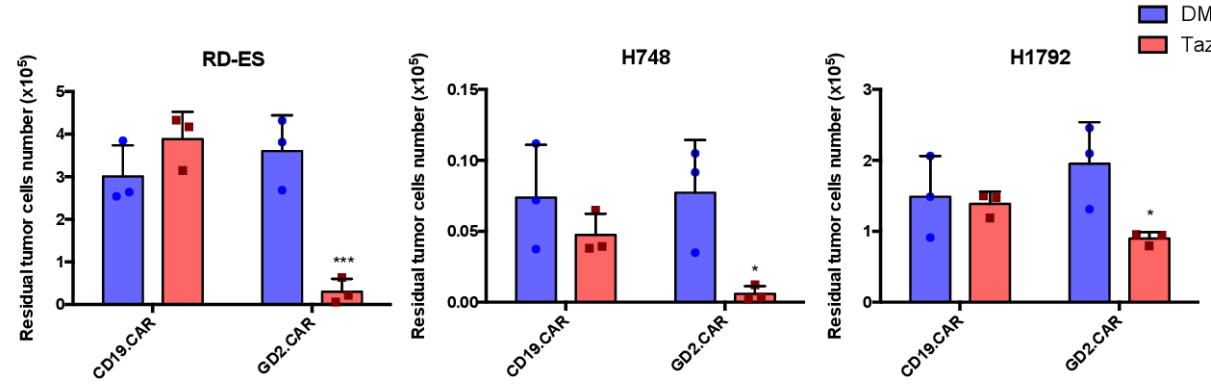

C

IFN $\gamma$

D

IL-2

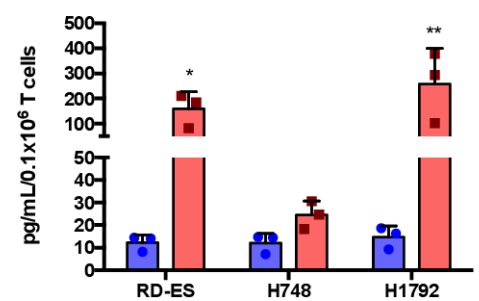

E

GD2.CAR + RD-ES GD2.CAR + H748 GD2.CAR + H1792

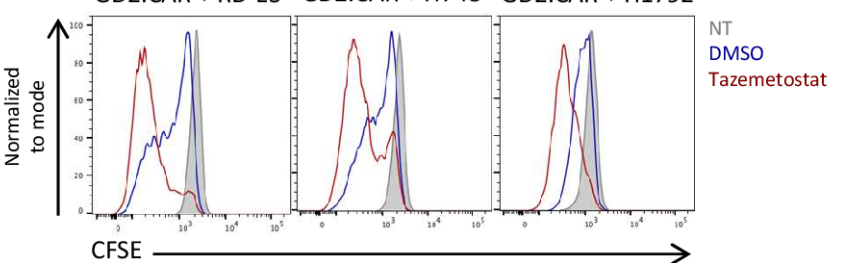

$\mathbf{F}$

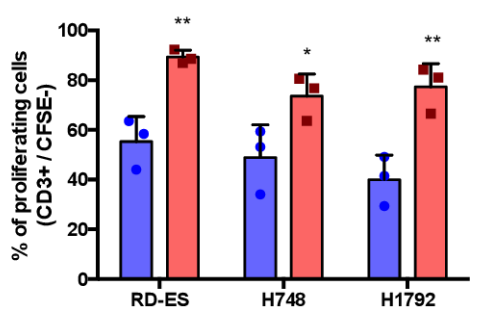

Figure 5 Upregulation of GD2 expression by EZH2 inhibition in GD2 ${ }^{\text {low/neg }}$ lung cancer cell lines makes them sensitive to GD2. CAR-T cell therapy. (A) GD2 expression on the cell surface of the SCLC cell line H748 and NSCLC cell line H1792 cultured with tazemetostat at 1 or $10 \mu \mathrm{M}$, respectively, or equivalent volumes of DMSO for 7 days (upper panel) and for 21 days (lower panel). The Ewing sarcoma cell line RD-ES was used as a positive control. The results are shown as percentages of positive cells and MFI of GD2 (GD2 MFI/isotype control MFI). (B) Lung cancer cell lines pretreated with tazemetostat or DMSO for 21 days were cocultured with either CD19.CAR-T cells or GD2.CAR-T cells at the T-cell to tumor cell ratio of 1 to 2 . On day 5, tumor cells $\left(\mathrm{CD} 276^{+}\right)$and T cells $\left(\mathrm{CD}^{+}\right)$were enumerated by flow cytometry. The Ewing's sarcoma cell line RD-ES was used as a positive control. Quantification of residual tumor cells are illustrated. Data represent mean $\pm S D\left(n=3,{ }^{*} p<0.05 ;{ }^{* \star *} p<0.001\right.$, tazemetostat vs DMSO pretreatment). (C, D) Summary of IFN $\gamma$ (C) and IL-2 (D) released by GD2.CAR-T cells in the culture supernatant after 24 hours of coculture with the tumor cell lines as measured by ELISA. Data represent mean $\pm S D\left(n=3,{ }^{*} p<0.05 ;{ }^{* *} p<0.01\right.$; ${ }^{* * * *} \mathrm{p}<0.0001$, tazemetostat vs DMSO pretreatment). (E) Representative CFSE dilution of CFSE-labeled GD2.CAR-T cells cocultured with tumor cell lines pretreated with tazemetostat or DMSO, for 4 days at 1 to 1 ratio analyzed by flow cytometry. (F) The percentages of CFSE dilution were measured relative to CFSE-labeled NT. Summary of CFSE-dilution assays. data represent mean $\pm S D\left(n=3,{ }^{*} p<0.05 ;{ }^{* *} p<0.01\right.$, tazemetostat vs DMSO pretreatment). CAR, chimeric antigen receptor; CFSE, carboxyfluorescein diacetate succinimidyl ester; DMSO, dimethyl sulfoxide; EZH2, Enhancer of zeste homolog 2; FSC, forward scatter; MFI, mean fluorescent intensity; NSCLC, non-small cell lung cancer; NT, non-transduced T cells; SCLC, small cell lung cancer. 
CAR-T cell therapy with selected epigenetic modulators deserves further preclinical investigation in lung cancers in an effort to minimize antigen escape in the context of this disease.

In conclusion, we demonstrated that our optimized GD2.CAR-T cells have excellent antitumor activity in vitro and in vivo in both SCLC and NSCLC tumor models. Our preclinical data open further venues for the clinical use of GD2-specific CAR-T cells as an immunotherapeutic strategy for GD2-expressing lung cancer.

\section{Author affiliations}

${ }^{1}$ Lineberger Comprehensive Cancer Center, University of North Carolina at Chapel Hill School of Medicine, Chapel Hill, North Carolina, USA

${ }^{2}$ Division of Pulmonary and Critical Care, University of North Carolina at Chapel Hill School of Medicine, Chapel Hill, North Carolina, USA

${ }^{3}$ Department of Pediatrics, University of North Carolina at Chapel Hill School of Medicine, Chapel Hill, North Carolina, USA

${ }^{4}$ Division of Oncology, University of North Carolina at Chapel Hill School of Medicine, Chapel Hill, North Carolina, USA

${ }^{5}$ Department of Microbiology and Immunology, University of North Carolina at Chapel Hill School of Medicine, Chapel Hill, North Carolina, USA

Acknowledgements This work was supported in part by V Foundation (JW, CVP, GD, BS). LR was supported in part by the 'Fondation de France', Lorraine University and Nancy University Hospital, France. CP was supported in part by the National Institutes of Health (NIH) R01CA215075, R01CA258451 and 1R41CA246848, and a North Carolina Biotechnology Translation Research Grant (NCBC TRG).

Contributors Conceptualization, LR, OT, JA, IJD, GF, HL, JW, GD, CVP and BS; methodology, investigation, LR, OT, JA, IJD, GF, HL, JW, GD, CVP and BS; writingoriginal draft, LR, OT, JW, GD, CVP, BS; writing-review and editing, all authors; resources, JA, IJD, GD, CVP and BS; supervision, GD, CVP and BS; guarantors, GD and BS.

Funding This work was supported in part by V Foundation (J.W. C.V.P, G.D., B.S.) L.R. was supported in part by the "Fondation de France", Lorraine University and Nancy University Hospital, France. C.V.P. was supported in part by the National Institutes of Health (NIH) R01CA215075, R01CA258451 and 1R41CA246848, and a North Carolina Biotechnology Translation Research Grant (NCBC TRG).

Competing interests GD is a paid consultant for Bellicum Pharmaceuticals, Tessa Therapeutics and Catamaran; BS is a paid consultant for Tessa Therapeutics. CP is founder in EnFuego Therapeutics and owns equity in the company. IJD has equity in Triangle Biotechnology. No potential conflicts of interest were disclosed by the other authors.

\section{Patient consent for publication Not applicable.}

Ethics approval This study was approved by UNC IRB 14-1755.

Provenance and peer review Not commissioned; externally peer reviewed.

Data availability statement Data are available on reasonable request.

Supplemental material This content has been supplied by the author(s). It has not been vetted by BMJ Publishing Group Limited (BMJ) and may not have been peer-reviewed. Any opinions or recommendations discussed are solely those of the author(s) and are not endorsed by BMJ. BMJ disclaims all liability and responsibility arising from any reliance placed on the content. Where the content includes any translated material, BMJ does not warrant the accuracy and reliability of the translations (including but not limited to local regulations, clinical guidelines, terminology, drug names and drug dosages), and is not responsible for any error and/or omissions arising from translation and adaptation or otherwise.

Open access This is an open access article distributed in accordance with the Creative Commons Attribution Non Commercial (CC BY-NC 4.0) license, which permits others to distribute, remix, adapt, build upon this work non-commercially, and license their derivative works on different terms, provided the original work is properly cited, appropriate credit is given, any changes made indicated, and the use is non-commercial. See http://creativecommons.org/licenses/by-nc/4.0/.

\section{ORCID iDs}

Loïc Reppel http://orcid.org/0000-0001-7951-6293
Giovanni Fucà http://orcid.org/0000-0002-1560-2253

\section{REFERENCES}

1 Siegel RL, Miller KD, Fuchs HE, et al. Cancer statistics, 2021. CA Cancer J Clin 2021;71:7-33.

2 Soneji S, Tanner NT, Silvestri GA, et al. Racial and ethnic disparities in early-stage lung cancer survival. Chest 2017;152:587-97.

3 DeSantis CE, Miller KD, Goding Sauer A, et al. Cancer statistics for African Americans, 2019. CA Cancer J Clin 2019;69:211-33.

4 American Cancer Society. Lung cancer survival rates | 5-year survival rates for lung cancer, 2021. Available: https://www.cancer.org/ cancer/lung-cancer/detection-diagnosis-staging/survival-rates.html

5 Paulson KG, Voillet V, McAfee MS, et al. Acquired cancer resistance to combination immunotherapy from transcriptional loss of class I HLA. Nat Commun 2018;9:3868.

6 Maude SL, Frey N, Shaw PA, et al. Chimeric antigen receptor T cells for sustained remissions in leukemia. N Engl J Med 2014;371:1507-17.

7 Ramos CA, Grover NS, Beaven AW, et al. Anti-CD30 CAR-T cell therapy in relapsed and refractory Hodgkin lymphoma. $J$ Clin Oncol 2020;38:3794-804

8 Raje N, Berdeja J, Lin Y, et al. Anti-BCMA CAR T-cell therapy bb2121 in relapsed or refractory multiple myeloma. N Engl J Med 2019;380:1726-37.

9 Fucà G, Reppel L, Landoni E, et al. Enhancing chimeric antigen receptor T-cell efficacy in solid tumors. Clin Cancer Res 2020;26:2444-51.

10 Kosti P, Maher J, Arnold JN. Perspectives on chimeric antigen receptor T-cell immunotherapy for solid tumors. Front Immunol 2018;9:1104.

11 Yu AL, Gilman AL, Ozkaynak MF, et al. Anti-GD2 antibody with GMCSF, interleukin-2, and isotretinoin for neuroblastoma. N Engl J Med 2010;363:1324-34.

12 Mount CW, Majzner RG, Sundaresh S, et al. Potent antitumor efficacy of anti-GD2 CAR T cells in $\mathrm{H} 3-\mathrm{K}_{2} 7 \mathrm{M}^{+}$diffuse midline gliomas. Nat Med 2018;24:572-9.

13 Yu J, Wu X, Yan J, et al. Anti-GD2/4-1BB chimeric antigen receptor $T$ cell therapy for the treatment of Chinese melanoma patients. $J$ Hematol Oncol 2018;11:1.

14 Rossig C, Kailayangiri S, Jamitzky S, et al. Carbohydrate targets for CAR T cells in solid childhood cancers. Front Oncol 2018;8:513.

15 Cheever MA, Allison JP, Ferris AS, et al. The prioritization of cancer antigens: a national cancer Institute pilot project for the acceleration of translational research. Clin Cancer Res 2009;15:5323-37.

16 Pule MA, Savoldo B, Myers GD, et al. Virus-specific T cells engineered to coexpress tumor-specific receptors: persistence and antitumor activity in individuals with neuroblastoma. Nat Med 2008;14:1264-70.

17 Louis CU, Savoldo B, Dotti G, et al. Antitumor activity and long-term fate of chimeric antigen receptor-positive $T$ cells in patients with neuroblastoma. Blood 2011;118:6050-6.

18 Heczey A, Louis CU, Savoldo B, et al. CAR T cells administered in combination with Lymphodepletion and PD-1 inhibition to patients with neuroblastoma. Mol Ther 2017;25:2214-24.

19 Gargett T, Yu W, Dotti G, et al. GD2-specific CAR T cells undergo potent activation and deletion following antigen encounter but can be protected from activation-induced cell death by PD-1 blockade. Mol Ther 2016;24:1135-49.

20 Cheresh DA, Rosenberg J, Mujoo K, et al. Biosynthesis and expression of the disialoganglioside GD2, a relevant target antigen on small cell lung carcinoma for monoclonal antibody-mediated cytolysis. Cancer Res 1986;46:5112-8.

21 Grant SC, Kostakoglu L, Kris MG, et al. Targeting of small-cell lung cancer using the anti-GD2 ganglioside monoclonal antibody 3F8: a pilot trial. Eur J Nucl Med 1996;23:145-9.

22 Yoshida S, Fukumoto S, Kawaguchi H, et al. Ganglioside G(D2) in small cell lung cancer cell lines: enhancement of cell proliferation and mediation of apoptosis. Cancer Res 2001;61:4244-52.

23 Wroblewski JM, Bixby DL, Borowski C, et al. Characterization of human non-small cell lung cancer (NSCLC) cell lines for expression of $\mathrm{MHC}$, co-stimulatory molecules and tumor-associated antigens. Lung Cancer 2001;33:181-94.

24 Borghaei H, Boyer M, Johnson M, et al. 359 AMG 757, a half-life extended bispecific T-cell engager (BiTE®) immune therapy against DLL3 in SCLC: phase 1 interim results. $J$ Immunother Cancer 2020;8:A384

25 Edelman M, Dvorkin M, Laktionov KK, et al. The antidisialoganglioside (GD2) antibody dinutuximab (D) for second-line treatment (2LT) of patients (PTS) with relapsed/refractory small 
cell lung cancer (Rr SCLC): results from Part II of the open-label, randomized, phase II/III distinct study. JCO 2020;38:9017.

26 Chen Y, Sun C, Landoni E, et al. Eradication of neuroblastoma by $T$ cells redirected with an optimized GD2-Specific chimeric antigen receptor and interleukin-15. Clin Cancer Res 2019;25:2915-24.

27 Diaconu I, Ballard B, Zhang M, et al. Inducible caspase-9 selectively modulates the toxicities of CD19-specific chimeric antigen receptormodified T cells. Mol Ther 2017;25:580-92.

28 Reynolds CP, Tomayko MM, Donner L, et al. Biological classification of cell lines derived from human extra-cranial neural tumors. Prog Clin Biol Res 1988;271:291-306.

29 Vera J, Savoldo B, Vigouroux S, et al. T lymphocytes redirected against the kappa light chain of human immunoglobulin efficiently kill mature $B$ lymphocyte-derived malignant cells. Blood 2006;108:3890-7.

$30 \mathrm{Du} \mathrm{H}$, Hirabayashi K, Ahn S, et al. Antitumor responses in the absence of toxicity in solid tumors by targeting $\mathrm{B} 7-\mathrm{H} 3$ via chimeric antigen receptor T cells. Cancer Cell 2019;35:221-37.

31 Xu Y, Zhang M, Ramos CA, et al. Closely related T-memory stem cells correlate with in vivo expansion of CAR.CD19-T cells and are preserved by IL-7 and IL-15.. Blood 2014;123:3750-9.
32 Kailayangiri S, Altvater B, Lesch S, et al. EZH2 Inhibition in ewing sarcoma upregulates $G_{02}$ expression for targeting with gene-modified T cells. Mol Ther 2019;27:933-46.

33 Heczey A, Courtney AN, Montalbano A, et al. Anti-Gd2 CAR-NKT cells in patients with relapsed or refractory neuroblastoma: an interim analysis. Nat Med 2020;26:1686-90.

34 Fraietta JA, Lacey SF, Orlando EJ, et al. Determinants of response and resistance to CD19 chimeric antigen receptor (CAR) T cell therapy of chronic lymphocytic leukemia. Nat Med 2018;24:563-71.

35 Krenciute G, Prinzing BL, Yi Z, et al. Transgenic expression of IL15 improves antiglioma activity of IL13R $\alpha 2-C A R$ T cells but results in antigen loss variants. Cancer Immunol Res 2017;5:571-81.

36 Hirabayashi K, Du H, Xu Y, et al. Dual targeting CAR-T cells with optimal costimulation and metabolic fitness enhance antitumor activity and prevent escape in solid tumors. Nat Cancer 2021;2:904-18.

37 Kailayangiri S, Altvater B, Wiebel M, et al. Overcoming heterogeneity of antigen expression for effective CAR T cell targeting of cancers. Cancers 2020;12:1075. doi:10.3390/cancers 12051075

38 Kroesen M, Büll C, Gielen PR, et al. Anti-GD2 mAb and vorinostat synergize in the treatment of neuroblastoma. Oncoimmunology 2016;5:e1164919. 